\title{
Study of obstetric and fetal outcome of twin pregnancy in a tertiary care centre
}

\author{
Gurpreet Kaur Nandmer, Anjali Vivek Kanhere*
}

Department of Obstetrics and Gynaecology, Peoples College of Medical Sciences and Research Centre, Bhopal, MP, India

Received: 23 September 2015

Accepted: 17 October 2015

\section{*Correspondence:}

Dr. Anjali Vivek Kanhere,

E-mail: kanhereanju@yahoo.com

Copyright: $\odot$ the author(s), publisher and licensee Medip Academy. This is an open-access article distributed under the terms of the Creative Commons Attribution Non-Commercial License, which permits unrestricted non-commercial use, distribution, and reproduction in any medium, provided the original work is properly cited.

\section{ABSTRACT}

Background: The past two decades have witnessed a sharp rise in the incidence of twin and higher order gestations. The progress and developments in assisted reproductive technology, availability and widespread use of ovulation inducing drugs and delayed childbearing are thought to be the causes responsible for the rise. Twin pregnancy is associated with increased maternal and perinatal morbidity and mortality as well as healthcare costs. Maternal complications like hypertensive disorders, anemia, gestational diabetes mellitus (GDM), preterm labour, preterm premature rupture of membranes (PPROM) and placental abruption increases. It is also responsible for repeated antenatal admissions, longer hospital stay, blood transfusions and increase in operative vaginal or cesarean delivery, post-partum hemorrhage and Hysterectomy. Twins have an increased risk of intraventricular hemorrhage, sepsis, necrotizing enterocolitis, respiratory distress syndrome and neonatal death. The objective of the study was to study the maternal and fetal outcome of twin pregnancy.

Methods: Retrospective analytical review of all twin deliveries at the teaching hospital medical college of Central India, over a period of 3 years between January 2010 and December 2012.There were 55 twin deliveries, data analysis regarding maternal age, parity, presentation, gestational age at delivery, obstetric complication mode of delivery, birth weights, and perinatal morbidity \& mortality was analyzed.

Results: Majority of patients $44(80 \%)$ were in age group of $20-30$ years. 55\% patients were booked and $62 \%$ were from urban area. $18(32 \%)$ patients could reach beyond 37 weeks, there were 21 (38\%) cases between 34 to 37 weeks and $16(29 \%)$ between 30 to 34 weeks of gestation. Preterm delivery was the commonest complication occurring in $67 \%$ of the cases. Cephalic presentation of both the babies occurred in $36 \%$ of the cases. $50 \%$ of the twins needed admission to NICU for various indications like prematurity, birth asphyxia, low birth weight, meconium staining of liquor \& delivery by caesarean section. In our study among the 55 twin births there were 16 (29\%) perinatal deaths and one maternal mortality.

Conclusions: Twin pregnancies are high risk pregnancies with more maternal and fetal complications. The use of antenatal care services, identification and anticipation of complications, intrapartum management and good NICU facilities will help to improve maternal and neonatal outcome in twin pregnancies.

Keywords: Twin pregnancy, Maternal and fetal outcome, Assisted reproductive technique 


\section{INTRODUCTION}

The past two decades have witnessed a sharp rise in the incidence of twin and higher order gestations. The progress and developments in assisted reproductive technology, availability and widespread use of ovulation inducing drugs and delayed childbearing are thought to be the causes responsible for the rise. ${ }^{1}$ Twin pregnancy is associated with increased maternal and perinatal morbidity and mortality as well as healthcare costs. ${ }^{2}$

Twin pregnancy imposes greater demand on maternal physiological system. There is an increase in occurrence of many complications like hypertensive disorders, anemia, gestational diabetes mellitus (GDM), preterm labour, preterm premature rupture of membranes (PPROM), and placental abruption. It is also responsible for repeated antenatal admissions, longer hospital stay, and blood transfusions. It is associated with increase in operative vaginal or cesarean delivery, post-partum hemorrhage and Hysterectomy. It eventually contributes to the three major causes of maternal mortality: postpartum hemorrhage, venous thromboembolism and hypertensive disorders. ${ }^{3}$

Twins have an increased risk of intrauterine fetal demise, twin transfusion syndrome (TTTS), congenital malformations, intraventricular hemorrhage, sepsis, necrotizing enterocolitis, respiratory distress syndrome and neonatal death. Surviving infants of preterm multi fetal have higher rates of developmental anomalies. ${ }^{4}$

The aim and objectives of the study was to study the outcome of twin pregnancy in terms of:
1. Average duration of gestation
2. Mode of delivery
3. Obstetric complications
4. Neonatal outcome

\section{METHODS}

The study was a retrospective analytical review of all twin deliveries at the teaching hospital medical college of Central India, over a period of 3 years between January 2010 and December 2012. Data was retrieved from patient's case-notes and supplemented by information from the labour ward, postnatal ward, theatre, and medical record department.

During the study period, there were 55 twin deliveries. Women with pregnancies less than 28 weeks of gestation were excluded from the study. A thorough evaluation of twin pregnancies was done regarding maternal age, parity, presentation, gestational age at delivery, obstetric complication mode of delivery, birth weights, and perinatal morbidity \& mortality.

\section{RESULTS}

Majority of patients $44(80 \%)$ were in age group of 20-30 years. $55 \%$ patients were booked and $62 \%$ were from urban area (Table 1). Period of gestation was as follows: $18(32 \%)$ patients could reach beyond 37 weeks, there were $21(38 \%)$ cases between 34 to 37 weeks and 16 (29\%) between 30 to 34 weeks of gestation.

Table 1: Demographic data of patients of twin pregnancy.

\begin{tabular}{|llll|}
\hline Age & & $\begin{array}{l}\text { No of patients } \\
\text { n=55 }\end{array}$ & Percentage \\
\hline & 20-24 yrs. & 26 & 46 \\
\hline & $25-30$ yrs. & 18 & 32 \\
\hline & $31-36$ yrs. & 11 & 20 \\
\hline Parity & Primi & 26 & 46 \\
\hline & multi & 29 & 55 \\
\hline ANC & Booked & 30 & 55 \\
status & & & 45 \\
\hline & Unbooked & 25 & 38 \\
\hline Rural & & 20 & 62 \\
\hline Urban & & 35 & \\
\hline
\end{tabular}

Table 2: Maternal morbidities in twin pregnancy.

\begin{tabular}{|lll|}
\hline Morbidity & Total & Percentage \\
\hline Preterm labour & 39 & 67 \\
\hline Anaemia & 17 & 30 \\
\hline $\begin{array}{l}\text { Hypertensive disorders in } \\
\text { pregnancy }\end{array}$ & 15 & 28 \\
\hline HELLP syndrome & 04 & 6 \\
\hline Polyhydramnios & 04 & 6 \\
\hline PROM & 09 & 16 \\
\hline APH & 02 & 4 \\
\hline Fetal distress & 02 & 8 \\
\hline
\end{tabular}

Table 3: Obstetric parameters: Presentation.

\begin{tabular}{|lll|}
\hline Presentation & Number N=55 & Percentage \\
\hline Vertex/ vertex & 20 & 36 \\
\hline Vertex/breech & 14 & 25 \\
\hline Breech/vertex & 07 & 13 \\
\hline Breech/breech & 11 & 20 \\
\hline Transverse/vertex & 02 & 04 \\
\hline Vertex/transverse & 01 & 02 \\
\hline
\end{tabular}

Preterm delivery was the commonest complication occurring in $67 \%$ of the cases. This was followed by anaemia $30 \%$ and hypertensive disorders in pregnancy (Pregnancy-induced hypertension, pre-eclampsia, and eclampsia) $28 \%$. Other morbidities were HELLP syndrome $6 \%$, polyhydramnios $6 \%$, APH $4 \%$, PROM $16 \%$, and fetal distress $8 \% .2$ patients had postpartum hemorrhage because of placenta previa needing internal iliac artery ligation followed by obstetric hysterectomy. 
Only one maternal mortality was there because of PIH, HELLP syndrome leading to DIC.

Cephalic presentation of both the babies occurred in $36 \%$ of the cases while vertex -breech presentation was seen in $25 \%$ (Table 3). The caesarean section rate for twin delivery was $45 \%$ (Table 4 ).

Table 4: Obstetric parameters: Mode of delivery.

\begin{tabular}{|lll|}
\hline Mode of delivery & Number N=55 & Percentage \\
\hline Preterm Vaginal & 16 & 29 \\
\hline Full-term Vaginal & 14 & 25 \\
\hline $\begin{array}{l}\text { Cesarean Section } \\
\text { Elective }\end{array}$ & 08 & 15 \\
\hline $\begin{array}{l}\text { Cesarean Section } \\
\text { Emergency }\end{array}$ & 16 & 29 \\
\hline $\begin{array}{l}\text { First Vaginal, } \\
\text { Second section }\end{array}$ & 01 & 02 \\
\hline
\end{tabular}

The commonest indication for caesarean section was assisted reproductive technology conception and fetal malpresentations.

The mean birth weight of the first baby was $1916.36 \mathrm{gm}$ while the mean birth weight of the second baby was $1685.94 \mathrm{gm}$.

Nearly $50 \%$ of the twins needed admission to NICU for various indications like prematurity, birth asphyxia, low birth weight, meconium staining of liquor \& delivery by caesarean section (Table 5).

Table 5: Perinatal morbidity.

\begin{tabular}{|llll|}
\hline Causes & Twin 1 & Twin 2 & Total \\
\hline Low birth weight & 22 & 24 & 46 \\
\hline $\begin{array}{l}\text { Respiratory distress } \\
\text { syndrome }\end{array}$ & 09 & 08 & 17 \\
\hline Septicemia & 04 & 06 & 10 \\
\hline $\begin{array}{l}\text { Transient tachypnea } \\
\text { of new-born }\end{array}$ & 04 & 05 & 09 \\
\hline Jaundice & 10 & 14 & 24 \\
\hline Anemia & 08 & 10 & 18 \\
\hline
\end{tabular}

\section{DISCUSSION}

In our study the overall rate of twin gestation was 18.03 per 1,000 deliveries seen in comparison with twin incidence quoted by different studies ranging from 11.4 to $19.37 .{ }^{5,6}$ Women in the age-group of $20-30$ years were the majority, accounting for $80 \%$ of total cases studied. Same findings were seen in the studies of Sholapurkar and Mitra. ${ }^{7,8}$ Preterm delivery was the commonest obstetric complication observed in the study as was the case in other studies carried out it is the most important factor contributing to the increasing perinatal mortality and morbidity in multiple pregnancies.
Cephalic presentation of both the babies occurred in $36 \%$ of the cases while vertex -breech presentation was seen in $25 \%$.

The caesarean section rate for twin delivery was $45 \%$. Study by Chaudhary reported rate of LSCS in 54\%, 37\% of women had caesarean section in the study done by Wanjari SA. ${ }^{6,10}$ Important indications for caesarean section were assisted reproductive technology conception and fetal malpresentations, premature rupture of membranes, hypertensive disorders of pregnancy and prior scar.

The mean birth weight of the first baby was $1916.36 \mathrm{gm}$ while the mean birth weight of the second baby was $1685.94 \mathrm{gm}$. same results were seen by Chaudhary. ${ }^{6}$ In our study, neonates in twin pregnancies, yielding a boy to girl ratio was 1:1. which is same as seen by Yamini S Patil other studies showed the number of male newborn was smaller in twin pregnancies. ${ }^{11}$

In our study among the 55 twin births (110 twins), there were $6(10 \%)$ stillbirths and $10(18 \%)$ early neonatal deaths i.e. $16(29 \%)$ perinatal deaths. The perinatal mortality observed by Chaudhary was $32.5 \%$. Wanjari reported rate of $18 \%{ }^{6,10}$ Perinatal mortality is an important indicator of maternal care; it reflects the quality of obstetric and pediatric care available. In our study $45 \%$ patients were unbooked and 38\% were from rural area, which emphasizes the need of early diagnosis and good antenatal care to improve the maternal and neonatal outcome.

\section{CONCLUSIONS}

Twin pregnancies are high risk pregnancies with more obstetrical complications compared to singleton pregnancies. The use of antenatal care services, identification and anticipation of complications, intrapartum management and good NICU facilities will help to improve maternal and neonatal outcome in twin pregnancies. Preterm delivery is the most common obstetric complication. Managing twin pregnancy is still a big challenge to the Obstetrician.

\section{Limitations}

Though it is a tertiary care medical centre the neonates who were transferred out were lost to follow up.

\section{ACKNOWLEDGEMENTS}

The authors would like to thank the patients for their participation. They would also like to thank Dr Vinod Narkhede Professor Community Medicine CMCH, Bhopal for proofreading and statistical analysis.

Funding: No funding sources

Conflict of interest: None declared 
Ethical approval: The study was approved by the Institutional Ethics Committee

\section{REFERENCES}

1. Daftary SN, Desai SV. Multiple fetal gestations. In: Daftary SN, Desai SV, eds. Textbook of Selected Topics in Obstetrics and Gynaecology-2, for Postgraduates and Practitioners. 19th ed. New Delhi: BI Publications Pvt Ltd. 2004:52-72.

2. American College of Obstetricians \& Gynaecologists Committee on Practice Bulletins-Obstetrics; Society for Maternal-Fetal Medicine; ACOG Joint Editorial Committee. ACOG Practice Bulletin \#56: Multiple gestations: complicated twin, triplet $\&$ higher order multifetal pregnancy. Obstet Gynaecol. 2004;104(4):869-83.

3. Walker MC, Murphy KE, Pan S, Yang Q, Wen SW. Adverse maternal outcomes in multifetal pregnancies. BJoG. 2004;111:1294-6.

4. ACOG Practice Bulletin 56: Multiple gestation: complicated twin, triplet, and high-order multifetal pregnancy. Obstel Gynecol. 2004;104:869-83.

5. Cunningham FG, Lenevo JK, Hauyh CJ, Rouse D, Blood S, Sponge C. Multifetal Gestation, Williams
Obstetrics, 23 ${ }^{\text {rd }}$ Edition, USA. The Macgraw-Hill Companies. 2010:859-889.

6. Choudhary VV, Sudhir S, Kaul R, Rathi S. Twin Gestation: A Challenging Task. Journal of Evolution of Medical and Dental Sciences. 2015;4(22):3897902.

7. Sholapurkar ML. Factors Affecting Perinatal Mortality in Multiple/Twin Pregnancy. J Obst, Gynaec, India. 1984;34:1020.

8. Mitra SR, Sikdar K. A Clinical Study of Twin Pregnancy. J Obst Gynaecol, India. 1980;30:636.

9. Ibrahim I, Oyeyemi A, Obibahi A. Twin Pregnancies In The Niger Delta Of Nigeria, A Four Year. Int J Womens Health. 2012;4:245-9.

10. Wanjari SA. Twin births: an overview. Int J Reprod Contracept Obstet Gynecol. 2014;3:995-7.

11. Patil YS, Nayak RG, Patil SK. Assessment of twin Pregnancy and Neonatal Outcome in Tertiary Care Center, KIMS, Karad. Journal of Evolution of Medical and Dental Sciences. 2014;3(74):15492-6.

Cite this article as: Nandmer GK, Kanhere AV. Study of obstetric and fetal outcome of twin pregnancy in a tertiary care centre. Int J Reprod Contracept Obstet Gynecol 2015;4:1789-92. 